\title{
Elevated levels of plasma homocysteine, deficiencies in dietary folic acid and uracil-DNA glycosylase impair learning in a mouse model of vascular cognitive impairment.
}

Nafisa M. Jadavji ${ }^{1}$, Tracy D. Farr ${ }^{1}$, Janet Lips ${ }^{1}$, Ahmed A. Khali1 ${ }^{1}$, Philipp Boehm-Sturm ${ }^{1}$, Marco Foddis ${ }^{1}$, Christoph Harms ${ }^{1}$, Martina Füchtemeier ${ }^{1,2}$, Ulrich Dirnagl ${ }^{1,2}$

${ }^{1}$ Department of Experimental Neurology, Center for Stroke Research Berlin, Charité Universitätsmedizin Berlin, Germany

${ }^{2}$ German Center for Neurodegenerative Diseases (DZNE), Berlin, Germany

Corresponding Author:

Nafisa M. Jadavji, PhD

Department for Experimental Neurology

Charité Universitätsmedizin Berlin

10117 Berlin GERMANY

Phone $+49(0) 30450560336$

Fax +49(0)30450560974

E-mail: nafisa.jadavji@charite.de 


\section{ABSTRACT}

Dietary deficiencies in folic acid result in elevated levels of plasma homocysteine, which has been associated with the development of dementia and other neurodegenerative disorders. Previously, we have shown that elevated levels of plasma homocysteine in mice deficient for a DNA repair enzyme, uracil-DNA glycosylase (UNG), result in neurodegeneration. The goal of this study was to evaluate how deficiencies in folic acid and UNG along with elevated levels of homocysteine affect vascular cognitive impairment, via chronic hypoperfusion in an animal model. Ung $+/+$ and Ung-/- mice were placed on either control (CD) or folic acid deficient (FADD) diets. Six weeks later, the mice either underwent implantation of microcoils around both common carotid arteries. Post-operatively, behavioral tests began at 3-weeks, angiography was measured after 5-weeks using MRI to assess vasculature and at completion of study plasma and brain tissue was collected for analysis. Learning impairments in the Morris water maze (MWM) were observed only in hypoperfused Ung-/- FADD mice and these mice had significantly higher plasma homocysteine concentrations. Interestingly, Ung+/+ FADD produced significant remodeling of the basilar artery and arterial vasculature. Increased expression of GFAP was observed in the dentate gyrus of Ung-/- hypoperfused and FADD sham mice. Chronic hypoperfusion resulted in increased cortical MMP-9 protein levels of FADD hypoperfused mice regardless of genotypes. These results suggest that elevated levels of homocysteine only, as a result of dietary folic acid deficiency, don't lead to memory impairments and neurobiochemical changes. Rather a combination of either chronic hypoperfusion or UNG deficiency is required. 


\section{INTRODUCTION}

Folates are an important B-vitamin involved in normal brain function. Specifically, folates play a role in nucleotide synthesis and metabolism of homocysteine, via methylation of homocysteine to methionine. This subsequently produces of S-adenosylmethionine (SAM), which plays a role in neurotransmitter synthesis and lipid metabolism [1]. Folate deficiency results in elevated levels of plasma homocysteine, which have been associated with cardiovascular disease [2], neurodegeneration [3], impaired cognitive function [4,5], the development of Alzheimer's disease $(\mathrm{AD})[6-8]$, and vascular dementia [9-11]. However, the neurodegeneration link remains controversial, since other studies have shown no association [12-14].

Several animal models with induced elevated levels of plasma homocysteine also exhibit impairments in short-term, spatial, and long term memory [15-18]. These impairments may be a result of the negative effects of elevated levels of homocysteine on vascular function [17,18]. Additionally, homocysteine can induce the accumulation of reactive oxygen species (ROS) in the brain [19],reduce levels of acetylcholine [15,16,20], inhibit nitric oxide [21], lead to excitotoxicity in the cell via repeated stimulation of the N-methyl-d-aspartate (NMDA) receptor $[19,22]$, promote cytotoxicity by oxidizing membrane lipids and proteins [23,24], increase levels of apoptosis [16,25], or reduce levels of SAM [26].

The mechanism through which folate deficiency leads to a decline in brain function is via the inability to repair DNA [27]. Accurate DNA repair and replication is important for healthy aging; when the rate of DNA damage exceeds the repair capacity of cells, it fundamentally changes the genetic code, which may lead to the loss of regenerative processes [28]. Neurons are post-mitotic cells, and their DNA can be lesioned primarily via oxidative processes, but also by cellular metabolism, ionizing or ultraviolet radiation [29]. Base excision repair is the primary repair mechanism in the brain that removes lesions from DNA. Several enzymes are required to convert the damaged DNA [30]. One enzyme that plays a crucial role in this process is uracilDNA glycosylase (UNG); it removes mismatched uracil from single and double stranded DNA [31]. Its inhibition in neuronal cultures results in neuronal death [32] and UNG knockout mice with elevated levels of homocysteine through dietary folate deficiency, show degeneration in the hippocampus as well as impairments in learning [33]. They also appear to be more susceptible to neurological injury [34]. Recently, an animal model of vascular cognitive impairment was described in mice [35], this model involves wrapping microcoils around the common carotid 
arteries in mice to induce a state of chronic hypoperfusion in the brain. Long-term effects of chronic hypoperfusion result in impairments in spatial working memory, as well as white matter damage, activated microglia and astrogila [36,37]. The purpose of this study is to examine whether elevated levels of plasma homocysteine through folic acid deficiency affect the progression of neurodegeneration via chronic hypoperfusion. The results of this study may help determine whether it is elevated levels of plasma homocysteine prior to effect progression of chronic hypoperfusion. 


\section{MATERIALS AND METHODS}

\section{Animal, diets and experimental design}

All experiments were approved by the Landesamt für Gesundtheit und Soziales Berlin and performed in accordance with the German Animal Welfare Act. Generation of UNG-deficient mice, was previously described [38]. The Ung null allele was back-crossed for more than 10 generations onto a C57BL/6 background. Wild-type mice were derived from the same animal facility, and Ung-/- mice have periodically been crossed with $\mathrm{C} 57 \mathrm{Bl} / 6$ mice to maintain genomic similarity, we crossed heterozygote mice to produce knockout mice used in this study. Females and males from multiple litters were used for each group in all experiments. At four-weeks-of-age Ung $+/+$ and Ung-/- mice were placed on a control (CD; $2 \mathrm{mg}$ folic acid/kg diet, Harlan Teklad) or folic acid deficient diet (FADD;0.3 mg folic acid/kg diet, Harlan Teklad). Mice were maintained on diets for six-weeks prior to surgery and remained on diets for the duration of the experiment (Table 1). In earlier work FADD has shown to decrease levels total folate in plasma as well as increased plasma homocysteine levels [39,40]. Animals were assigned into groups randomly using a custom written program (Mauselotto) and housed in a temperature $\left(22 \pm 2{ }^{\circ} \mathrm{C}\right)$, humidity $(55 \pm 10 \%)$, light $(12 / 12 \mathrm{~h}$ light/dark cycle) controlled environment. Animals were given ad libitum access to food and water. Beginning at 3 weeks after surgery, animals began a battery of behavioral tests, and at the conclusion of the study (6 weeks later), MRI was acquired and brain tissue and plasma were collected (Fig. 1).

\section{Chronic hypoperfusion via bilateral common carotid artery stenosis}

Animals were anaesthetized with isoflurane (1.5\%) in a 70:30nitrous oxide : oxygen mixture and core body temperature was maintained at $37.0 \pm 0.2{ }^{\circ} \mathrm{C}$ using an automated heat blanket with temperature feedback (Harvard Apparatus). Animals were placed in a supine position, and both carotid arteries were carefully exposed through a midline incision. Chronic hypoperfusion was induced by wrapping microcoils (180 $\mu \mathrm{m}$ inner diameter, Sawane Spring Company) around both carotid arteries [35]. The corresponding sham procedure resulted in microcoils being placed next to the carotid arteries. Finally, local anesthetic was applied to the wound after suturing the incision. All animals received $6 \mathrm{mg} / \mathrm{mL}$ of Paracetamol in the drinking water one day prior to, and up to three days post-surgery to assist with post-operative pain.

\section{Behavioural analysis}

\section{Rotarod}


Animals were tested on a standard rotarod (TSE Systems). The metal rotarod cylinder was 3.5 $\mathrm{cm}$ in diameter and $6 \mathrm{~cm}$ wide. The cylinder was positioned $13.5 \mathrm{~cm}$ from the ground by a Plexiglas container and moved by a rubber belt connected to a small motor. Animals were tested on an accelerating rotarod (4 to $40 \mathrm{rpm}$ ) over $5 \mathrm{~min}$ and the latency to fall was recorded. Animals were tested on a single day with three separate trials and an inter trial interval of $5 \mathrm{~min}$ [41].

\section{Skilled ladder beam task}

The ladder-rung apparatus was composed of two Plexiglas walls $(69.5 \times 15 \mathrm{~cm})$. Each wall contained holes located along the bottom edge that could be filled with metal bars, thus resembling a horizontal ladder. The entire apparatus was placed atop two standard mouse housing cages. Crossings from the empty cage back to the home cage were video-recorded, with the camera positioned at as light ventral angle so that all 4 limbs could be recorded at the same time. Three trials (full crossings) were scored per animal and steps around the pauses were omitted from the scoring. Movement score and percent error was calculated for each trial as previously described [42].

\section{Morris water maze}

The Morris water maze (MWM) apparatus was a $120 \mathrm{~cm}$ in diameter, $60.5 \mathrm{~cm}$ high circular swimming pool. Cues were present at fixed positions and the pool was filled to a depth of $29 \mathrm{~cm}$ with $25^{\circ} \mathrm{C}$ opaque water. A clear Plexiglas platform $(10 \times 10 \mathrm{~cm})$ was submerged at a fixed position with the top located $1 \mathrm{~cm}$ beneath the surface of the water in the center of one of the four quadrants. Animal swim paths were tracked with a computer based system (TSE Systems). Mice were trained to find the hidden platform over 7 days, with 3 trials per day and an inter-trial interval of $30 \mathrm{~min}$. Each trial consisted of a maximum of $90 \mathrm{~s}$ and was randomly started from one the quadrants with the animal facing the wall. If after $90 \mathrm{~s}$ an animal did not reach the platform it was guided there. After reaching the platform animals were allowed to remain there for10 s [43]. The mice were dried with a towel and placed under a heat lamp $\left(37^{\circ} \mathrm{C}\right)$ between each trial. On day 8 a probe trial (spatial probe) occurred, the platform was removed and mice were allowed to swim for $90 \mathrm{~s}$.

\section{Open field}

The open field box, measuring $32.5 \times 41 \times 51 \mathrm{~cm}$, was made of grey Plexiglas. The bottom of the box was divided into 16 equal squares. At the start of testing, individual animals were placed in the middle of the open field box and video recorded for $5 \mathrm{~min}$. Video recordings were scored 
for vertical activity (number of rears), over-all activity (total number of squares crossed), fields entered in both the center and outside squares, and \% time spent in the center and outside squares [44].

\section{Elevated plus maze}

The elevated plus maze, made of gray Plexiglas, consisted of four arms $(30 \times 6 \mathrm{~cm})$ shaped in the form of a that was elevated $50 \mathrm{~cm}$ from the floor. Two opposite arms were enclosed by walls (10 cm high), the remaining two arms were open. The connecting (open) center area measured 6 $\times 6 \mathrm{~cm}$. At the start of each test, animals were placed in the center area facing an open arm. Trials lasted for 5 min and the number of open and closed arm entries, as well as time spent in each arm, was recorded [45].

\section{Magnetic resonance imaging (MRI)}

All MRI experiments occurred approximately 5 weeks post-operatively on a $7 \mathrm{~T}$ system (Bruker BioSpin). Anesthesia was again achieved using isoflurane, and body temperature and respiratory rate were monitored with MRI compatible equipment (Small Animal Instruments, Inc.). A 20 mm diameter quadrature volume coil was used for radio frequency transmission and reception (RAPID Biomedical). The imaging protocol consisted of a T2weighted 2D-rapid acquisition relaxation enhancement (RARE) sequence (32 contiguous $0.5 \mathrm{~mm}$ thick slices, image matrix: $256 \times 196$ interpolated to $256 \times 256$, repetition time/echo time: TR/TE: 4200/36 ms, RARE factor of 8, 4 averages, resolution: $100 \mu^{2}, 6: 43 \mathrm{~min}$ ), and a 3D time of flight (TOF) angiography sequence (image matrix: $256 \times 196 \times 128$ interpolated to 2563 , TR/TE: $15 / 2.5 \mathrm{~ms}$, $\alpha$ : Flipangle: $20 \circ$, resolution: $\left.100 \mu^{3}, 6: 08 \mathrm{~min}\right)$.

\section{Image analysis}

Whole brain and hippocampal volumes were calculated by manually drawing regions of interest on the $\mathrm{T}_{2}$ scans using ImageJ freeware (National Institutes of Health). Raw angiography data was exported into FSL (FMRIB, Oxford) software and the FLIRT tool was used to co-register all data sets. Subsequently, the images were exported into ImageJ and the same volume was selected to build a maximum intensity projection (MIP) of the circle of Willis using a custom written Plugin. A threshold that corresponded to roughly half of the signal in all the images (9000) was chosen to exclude most of the brain tissue and convert the MIP to a binary image. Some manual processing was performed, together with the original image, to remove any voxels that were not part of the vascular network. The overall size of the circle of Willis (vasculature) and basilar 
artery were calculated from the binary image by counting the number of voxels with a value of 1 , and the volumes were corrected for co-registration using the determinant of the FSL transformation matrix.

\section{Brain morphology}

At the conclusion of the experiments, mice were deeply anaesthetized with isoflurane, terminal blood samples were collected via cardiac puncture in potassium ethylenediaminetetraacetic acid (EDTA) coated tubes and the brain was removed. The cortex, hippocampus and striatum were excised from the left hemisphere and frozen for mitochondrial DNA, gene expression or protein analyses. The right hemisphere was fixed in 4\% paraformaldehyde for $24 \mathrm{~h}$, processed, and then sectioned at $5 \mu \mathrm{m}$ thick. Sections were stained using Cresyl Violet for assessment of thickness of the $\mathrm{CA} 1, \mathrm{CA} 3$ and dentate gyrus regions of hippocampus as well as the cerebellar internal granular layer, as previously described [16]. The degree of cerebellar foliation was determined by counting the number of clearly defined lobes. Another set of sections was stained with Klüver-Barrera $(\mathrm{KB})$ to assess myelination. All sections were assessed at the same level along the sagittal axis.

\section{Immunohistochemistry}

Reactive astrogliosis was detected using glial fibrillary acidic protein (GFAP) staining. Sections were deparaffinized in fresh Roti-Histol (Carl Roth) $(\times 3)$ for 5 min each, then rehydrated in absolute alcohol $(\times 3)$ for 5 min followed by incubation in $96 \%, 80 \%$ and $70 \%$ alcohol for $2 \mathrm{~min}$ each. Slides were washed briefly in phosphate buffered saline (PBS). Antigen retrieval was performed using $10 \times$ Antigen Unmasking solution (Biologo) for $20 \mathrm{~min}$ at $95^{\circ} \mathrm{C}$ followed by 20

min at room temperature. Slides were rinsed in PBS $(\times 3)$ for $5 \mathrm{~min}$. Nonspecific sites were blocked with 5\% normal goat serum for $30 \mathrm{~min}$ and then incubated with anti-GFAP (polyclonal rabbit antibody, Dako) at a concentration of 1:100 overnight at $4 \circ \mathrm{C}$ in a humidified chamber. Slides were incubated with a biotinylated goat anti-rabbit secondary at a dilution of 1:200 for $2 \mathrm{~h}$ at room temperature, followed by incubation with avidin biotin complex $(\mathrm{ABC}$; Vector Laboratories) at a 1:50 dilution for $1 \mathrm{~h}$ at room temperature. Staining was visualized using diaminobenzdine (DAB; Vector Lab-oratories). All sections were checked for GFAP positive cells at a magnification of $200 \mathrm{X}$; five to six mice per genotype group were examined.

\section{Quantitative real-time $R T-P C R$}


RNA was extracted from frozen cortex $(\sim 30 \mathrm{mg})$ using the RNeasy Lipid Tissue Mini kit (Qiagen). cDNA synthesis and real-time PCR reactions were performed as described [46]. Primers were as follows for tissue inhibitor of metalloproteinase 1 and 3 (TIMP1; sense 5'-TTG GGT ACC CTG GCT ATC AG-3'and anti-sense 5'-TTG CTG ATG CTC TTG TCT GG-3'), (TIMP3; sense 5-TGTGCA ACT TTG TGG AGA GG-3'and antisense 5'-AAT TGC AAC CCAGGT GGT AG-3'), IQ motif and SEC7 domain containing protein1 (IQSEC1; sense 5'GAT CCCT GCA TCA TGG TCT T and anti-sense 5'-CTT CAA AAA GCC GGC AGT AG3'), Poly ADP-ribose polymerase 1 (PARP-1; Sense 5'-ACG AGC TGA AGA AAG CGTGT-3' and antisense 5'-TGC TGC TGG TTG AAG ATG AG-3'), DNA polymerase beta (POLB; sense 5'-TTT CAG AAG AGG CGC AGAGT-3' and antisense 5'-TGC TGG ATT CTG ACG TGA AG-3') andglyceraldehyde-3-phosphate dehydrogenase (Gapdh; sense 5'-CATGGC CTT CCG TGT TCC TA-3' and antisense 5'-CCT GCT TCA CCA CCTTCT TGA T-3') were designed using Primer 3 and NCBI software. Target gene expression was normalized using the housekeeping gene Gapdh.

\section{Western blotting}

Protein extracts from the cortex $(\sim 50 \mathrm{mg})$, hippocampus $(\sim 15 \mathrm{mg})$ and striatum $(\sim 10 \mathrm{mg})$ were prepared, separated by SDS-PAGE and transferred to nitrocellulose membranes as previously described [16]. Primary antibodies were ADP-ribosylation factor 6 (Arf6; Cell Signaling Technology), Aquaporin-4 (AbCam), Metalloproteinase-9 (MMP-9; AbCam) and GAPDH (Cell Signalling Technology). Secondary antibodies were horseradish peroxidase (HRP)-conjugated donkey anti-rabbit IgG (GE Healthcare) and HRP-conjugated donkey anti-goat IgG (Santa Cruz Biotechnology), as appropriate. Detection was achieved using Western Lighting PlusECL

(Perkin Elmer). Bands were quantified by densitometry using freeware ImageJ (National Institutes of Health) and normalized to GAPDH. Two experiments were performed for all cortical protein levels.

\section{Plasma homocysteine levels}

Blood samples were centrifuged at $7000 \times \mathrm{g}$ for $7 \mathrm{~min}$ at $4 \circ \mathrm{C}$ to obtain the plasma, which was subsequently frozen until analysis. High performance liquid chromatography (HPLC) was used to measure homocysteine concentrations (Labor 28, Berlin).

\section{Mitochondrial DNA damage}


DNA was isolated from cortical and hippocampal tissue using the DNA Tissue and Blood kit (Qiagen). Mitochondrial DNA (mtDNA) damage was quantified as previously described [47]. Briefly, equal amounts of DNA were incubated with HaeII (New England Biolabs), after which a long strand (10 kB) (sense, 5'-GCCAGC CTG ACC CAT AGC CAT ATT AT-3'; antisense, 5'GAG AGA TTTTAT GGG TGT ATT GCG-3') and short strand (200 bp; sense, 5'-CCCAGC TAC TAC CAT CAT TCA AGT-3'; antisense 5'-GAT GGT TTG GGAGAT TGG TTG ATG T-3') was amplified. DNA products were then quantified, number of lesions in short mtDNA was quantified and normalized to long strand.

\section{Statistical analysis}

Two investigators, blinded to group assignment, performed analysis of all behavioral data, morphology, immunohistochemistry and Western blot experiments. Statistical analysis was performed using Graph Pad 6.0 or SPSS 21 software. A two-way analysis of variance (ANOVA) was used to compare both the diet and surgery groups within each genotype. Two way repeated measure ANOVA was used for the Morris water maze daily latency measurements. Significant main effects in the ANOVAs were followed by the Bonferroni post-hoc test to determine whether statistically significant differences existed between the groups. Subsequently, data from males and females was separately analyzed to determine if there were differences between genders. We used 2-wayANOVA to compare both the diet and surgery for each sex and genotype group. In all analyses, $\mathrm{p} \leq 0.05$ was considered significant. All data are presented as mean \pm standard error of the mean (SEM). 


\section{RESULTS}

\section{Neither chronic hypoperfusion or FADD impairs sensorimotoror skilled motor function}

Sensorimotor function in mice was assessed by the rotarod and skilled motor function using the ladder beam walking task. We observed no difference in the latency to fall off the accelerating rotarod between any of the groups for either Ung+/+ or Ung-/- mice (data not shown). Furthermore, the ladder beam task showed no differences between any of the groups for either Ung $+/+$ or Ung-/- mice in the overall movement score or the percentage error in the skilled ladder beam task (data not shown).

\section{A combination of $U N G$ deficiency, $F A D D$ and hypoperfusion result in spatial learning} impairments in the Morris water maze task

During the seven days of testing, no differences in spatial learning between Ung $+/+$ groups were observed; daily escape latency was equal and decreased with time as the mice learned the location of the platform (Fig. 2A). Probe trial testing on day 8 revealed no differences in the amount of time Ung $+/+$ animals spent in the target quadrant (Fig. 2C). In general, Ung-/- mice needed more time to acquire the paradigm over the 7 test days (Fig. 2B), suggesting slower learning when compared to Ung $+/+$ mice. There was a significant surgery main effect for Ung $-/-$ mice (Fig. 2B, $\mathrm{F}(1,41)=4.75, \mathrm{p}<0.05$ ) and a non-significant dietary main effect $(\mathrm{F}(1,41)=3.88, \mathrm{p}=0.056)$ for Ung-/- mice daily escape latencies. FADD microcoil mice exhibited the greatest latencies throughout the majority of the testing period, suggesting that both diet and hypoperfusion contributed to this delay in learning in addition to Ung deficiency. It is interesting to note that during the probe trial there was a significant interaction of surgery and diet in the percent total time spent in the target quadrant for the Ung-/- mice $(F(1,39)=9.09, \mathrm{p}<$ 0.01). CD microcoil mice spent the most time in the target platform quadrant (Fig. $2 \mathrm{D}, \mathrm{p}<0.01$ ).

\section{Anxiety decreases with a combination of hypoperfusion and FADD in Ung-/- mice}

No changes in entries into the center squares of the open field were observed between groups of Ung $+/+$ mice (Fig. 3A). However, there was a significant main effect of surgery (Fig. 3B; F(1, $59)=5.37, \mathrm{p}<0.05)$ in Ung $-/-$ mice. Interestingly, Ung-/- microcoil mice made significantly more entries into the interior squares of the open field when compared to the sham mice, indicating reduced anxiety in the microcoil group [48]. Additionally, there was an interaction between diet and surgery for the number of entries into the closed arm of the elevated plus maze 
(Fig. 3D, $F(1,60)=5.56, \mathrm{p}<0.05)$. On average FADD microcoil mice made significantly less entries into the closed arm. No difference between Ung $+/+$ groups was observed (Fig. 3C).

\section{Increased plasma homocysteine levels in mice with a FADD}

After 3 months of diet, there was a significant main effect on plasma homocysteine of diet $(\mathrm{F}(1,20)=23.8, \mathrm{p}<0.0001)$ in Ung $+/+$ mice. Specifically, Ung $+/+$ mice on a FADD had significantly elevated levels of plasma homocysteine when compared to mice on a CD (Fig. 4A, $\mathrm{p}<0.01)$. Similar results were observed in Ung-/- mice. There was a main effect of diet $(\mathrm{F}(1,36)=13.38, \mathrm{p}<0.001)$ and animals on FADD exhibited higher levels of plasma homocysteine than those on a CD (Fig. 4B, p < 0.01). Indeed, Ung-/- mice on a FADD had highest overall plasma homocysteine, this indicates that FADD significantly elevates plasma homocysteine levels, and that this occurs to a much higher degree when the mice are UNGdeficient.

\section{FADD increases arterial remodeling in Ung $+/+$ mice}

Hypoperfusion is known to induce arterial remodeling in response to changes in shear stress, therefore, the overall size of the basilar artery and circle of Willis vasculature were measured using angiography in each of the groups. Interestingly, diet had amore profound effect on basilar artery size increases than hypo-perfusion (Fig. 5). A significant main effect of diet for basilar artery size $(F(1,11)=9.75, p<0.01)$ was observed. Sham and microcoil mice on a FADD had the largest basilar arteries (Fig. 5E, p < 0.05). There was also a significant main effect of diet $(F(1,11)=8.71, p<0.05)$ on the overall size of the circle of Willis vasculature. FADD microcoil mice had the largest vascular networks (Fig. 5F, p < 0.05). This indicates that diet contributed to the expansion of the overall vascular network. Strikingly, these arterial changes were not manifested in Ung-/- mice, suggesting that Ung is required for this process tooccur

\section{Comparable brain volume and morphology, but increased GFAP immunoreactivity in hypoperfused mice on FADD}

There was no difference between groups in overall brain and hippocampal volume of Ung $+/+$ mice. Interestingly, among the Ung-/-mice, there was a surgery main effect for brain volume (data not shown, $\mathrm{F}(1,12)=7.99, \mathrm{p}<0.05)$. The difference between groups was approximately 20 mm3with brains of hypoperfused mice being larger, which may be a result of edema. No difference in hippocampal volume was observed between groups. There were no differences in cerebellar (foliation and thickness of interior granular layer) or hippocampal morphology 
(thickness of CA1 CA3 and dentate regions) between groups for Ung+/+ and Ung-/- mice (data not shown). We assessed myelination using Klüver Barrera staining, and observed no differences in staining intensity or white matter rareificiation (data not shown) in any of the animals irrespective of group. Qualitative analysis revealed that there was, however, substantial increased in GFAP immunoreactivity within the dentate gyrus of Ung-/- mice. Microcoil mice on had approximately $33 \%$ on CD (Fig. 6B) and $80 \%$ on FADD (Fig. 6D) more positive stained cells, when compared to $0 \%$ in CD sham mice (Fig. 6A). Mice in the FADD sham group had $60 \%$ more positive stained cells (Fig. 6C). These results imply that hypoperfusion induces reactive gliosis in the hippocampus, which is exacerbated by a FADD.

\section{Minimal changes in $m R N A$ expression and no mitochondrial DNA damage in hypoperfused mice}

We observed no differences between groups of Ung+/+ mice in cortical mRNA expression of PARP-1, POLYB, TIMP1 and 3 (data not shown), or IQSEC1. Similar findings were present in Ung-/- mice PARP-1, POLYB, TIMP1 and 3 (data not shown). We observed a surgery main effect in Ung-/- mice for IQSEC1 mRNA expression $(F(1,15)=17.40, p<0.001)$; levels were higher in the hypoperfused mice. It is important to note that the fold change between sham and microcoil mice was approximately 1.03, indicating that this change in gene expression may not be biological significant [49]. Regard-less, we followed up the IQSEC1 mRNA changes in the Ung-/- mice by measuring protein levels of ADP-ribosylation factor 6 (Arf6). However, we observed no difference between groups, indicating that the increase IQSEC1 mRNA expression is not translated to the protein. Previously it has been shown that a UNG and folate deficiency results in mitochondrial DNA (mtDNA) mutagenesis [50,51]. Using a quantitative PCR-based technique we measured mtDNA damage in cortical and hippocampal tissue of Ung $+/+$ and Ung-/- mice. Interestingly, we observed little to no damage in all samples.

\section{Increased cortical MMP-9 protein levels in hypoperfused mice}

We measured protein levels of MMP-9 in the cortex, hippocampus and striatum of Ung $+/+$ and Ung-/- mice. Changes in MMP-9 protein levels were only observed in cortical tissue. There was a significant main effect of diet $(\mathrm{F}(1,12)=11.74, \mathrm{p}<0.01)$ in Ung $+/+$ mice. FADD and microcoils resulted in highest levels of MMP-9 expression when compared to CD sham (Fig. 7A, $\mathrm{p}<0.01)$ and microcoil $(\mathrm{p}<0.05$, Fig. 7A) groups. Similar results were found for the Ung-/mice; there was a significant main effect of diet $(F(1,16)=13.85, \mathrm{p}<0.01)$ and surgery $(\mathrm{F}(1,16)=$ 5.48, $\mathrm{p}<0.05)$. Overall, FADD micro-coil mice had increased MMP-9 protein levels when 
compared to $\mathrm{CD}$ sham mice (Fig. 7B, $\mathrm{p}<0.05)$ and FADD sham mice $(\mathrm{p}<0.05)$. This suggests that a FADD produced increased MMP-9, and this was exacerbated by hypoperfusion.

\section{Sex differences}

Sex differences were analyzed since we used male and female mice in the study. Male and female $\mathrm{UNG}+/+$ and Ung-/- mice per-formed similarly on the rotarod task, no change was observed between groups (data not shown). However, there were significant diet $(\mathrm{F}(1,17)=$ $6.71, \mathrm{p}<0.05)$ and surgery $(\mathrm{F}(1,17)=4.90, \mathrm{p}<0.05)$ main effect on daily escape latencies in the MWM of female Ung-/-mice (Fig. 8B). Additionally, there was a significant diet and surgery interaction in the percent total time female Ung-/- mice spent in the platform quadrant during the probe trial $(\mathrm{F}(1,18)=11.79, \mathrm{p}<0.01)$. More specifically, female mice on a CD with chronic hypoperfusion spent more time in platform quadrant compared to CD Sham (Fig. 8D, p $<0.01)$ and FADD chronic hypoperfused mice $(\mathrm{p}<0.01)$. There was a significant diet and surgery inter-action in the number of entries into center squares of the open field of female Ung- - mice $(\mathrm{F}(1,25)=12.63, \mathrm{p}<0.01)$. Female mice on a control diet with chronic hypoperfusion made more entries into inside squares when compared to CD Sham (Fig. 8F, p < $0.05)$ and FADD chronic hypoperfusion mice $(\mathrm{p}<0.05)$. There were no sex differences in homocysteine concentrations, male and female FADD UNG+/+ and Ung-/- mice both had the highest homocysteine concentrations (data not shown). Basilar artery volumes in $\mathrm{UNG}+/+$ males were more affected by chronic hypoperfusion than females $(F(1,10)=14.42, p<0.01)$, whereas vasculature remained unchanged in both sexes. Whole brain volume was significantly increased in Ung-/- females $(\mathrm{F}(1,12)=12.9, \mathrm{p}<0.05)$ as a result of chronic hypoperfusion. There were no sex differences in mRNA expression of IQSEC1 and protein levels MMP-9 in cortical tissue, as well as GFAP expression within the dentate gyrus of the hippocampus of $\mathrm{UNG}+/+$ and Ung-/- mice. 


\section{DISCUSSION}

This study evaluated the combined effects of elevated levels of plasma homocysteine produced by folic acid deficiency and DNA repair enzyme deficiency in a mouse model for vascular cognitive impairment via chronic hypoperfusion. A combination of chronic hypoperfusion and FADD that produced impaired spatial learning in the Ung-/- mice on the MWM. As anticipated, dietary folic acid deficiency resulted in elevated levels of plasma homocysteine in both wild-type and Ung knockout mice. Moreover, the FADD produced arterial remodeling only in wild-type mice, suggesting that Ung is required for this process. Ung-/- and FADD combination resulted in increased levels of GFAP expression in the dentate gyrus of Ung-/- mice, and increased cortical protein levels of MMP-9 in, the latter of which was also present in FADD Ung+/+ mice. The overall results of this study suggest that elevated levels of homocysteine (due to a FADD) act in conjunction with impaired DNA repair to cause learning impairments in a mouse model of vascular cognitive impairment. Chronic hypoperfusion and FADD resulted in some extracellular matrix degradation within the cortex, due to the accumulation of MMPs and increased presence of reactive gliosis in dentate gyrus of both wild-type and knockout mice. Elevated levels of homocysteine via folic acid deficiency are not solely responsible for impairment.

Increased levels of plasma homocysteine have been associated with dementia in many epidemiological studies [9,17,52]. A number of possible mechanisms of detrimental homocysteine action have been proposed, however, most of these studies been done in nondamaged animals, or under in vitro conditions. The present study is the first to show the effects of elevated levels of plasma homocysteine via dietary folic acid deficiency in a progressively degenerative neurovascular disease model in UNG-deficient mice. One of the findings that was most interesting from the present study was that the FADD with the corresponding 
hyperhomocysteinemia was able to increase arterial remodeling to an even greater extent than hypoperfusion, which is well known to induce this response phenomenon $[53,54]$. However, it is conceivable that elevated levels of plasma homocysteine can affect arterial remodeling, for example, homocysteine has been shown to increase smooth muscle cell proliferation by reducing levels of nitric oxide [55].Additionally, increased levels of homocysteine result in reduced levels of SAM, a global methyl donor, therefore altering the DNA methylation pattern, which could also affect vascular function [2].Interestingly, the remodeling we observed was not present in Ung-/- mice, even in combination with a FADD, suggesting that Ung is required for remodeling, and DNA repair must play a major role in this process. Previous work has described increased mutation frequency in Ung-/- when mouse embryonic fibroblasts are cultured in a folic acid deficient medium [33], this also supports the notion that intact DNA repair is necessary for proper endothelial and smooth muscle synthesis and function. More changes in microvasculature could be expected since there is remodeling of large vessels.

Folic acid deficiency is well known for its role in learning and memory [56]. In the present study, we found that a FADD together with hypoperfusion induced impairments in spatial learning on the MWM only in Ung-/- mice. As there were no differences between groups in swim speed, or on the rotarod and skilled ladder beam task, therefore this response was likely not due to differences in sensorimotor ability. It appears that all three factors (diet, hypoperfusion, and UNG deficiency) are required to interfere with spatial learning. An earlier study by [33] also confirmed this as it showed that Ung $+/+$ and Ung-/- mice on FADD did not show impairments in spatial learning on a similar paradigm of the MWM. The same is true when mice are exposed only to chronic hypoperfusion [37]. Interestingly, hypoperfused mice overexpressing the mutant human amyloid precursor protein showed impairments in spatial learning on the Barnes maze [57]. The fact that there was a significant interaction between diet and surgery for the percentage 
time Ung-/- mice spent in the target quadrant during the probe trial of the MWM is interesting. Generally, more time spent in the target quadrant during the probe trial is interpreted positively as it implies intact spatial reference memory. CD hypoperfused mice spent more time in the target quadrant compared to FADD hypoperfused animals. Taking into account that the FADD hypoperfused mice took longer to learn where the platform was during the prior 7-day training period, we think that this slower learning is further highlighted by the limited amount of time spent in the target quadrant during the probe trial. However, both CD and FADD sham mice spent approximately $25 \%$ of their total time in the tar-get quadrant, which is roughly equivalent to chance and that the difference may not be relevant. Another possible explanation for the discrepancy could be that FADD and/or hypoperfusion is influencing other aspects of behavior not related to spatial memory, such as motivation, attention, mobility, or anxiety in the Ung-/-.We found that there was decreased anxiety in the hypoperfused Ung-/- mice when compared to shams. Indeed, decreased anxiety has been reported following hypoperfusion by other groups $[36,58]$, though, it has been suggested that hypoperfusion may simply be increasing activity levels, rather than anxiety, by another group that observed hypoperfused mice made more entries into both the open and closed arms of the elevated plus maze [59]. We did not observe differences in activity between groups during any of the tests. At any rate, deficits in the MWM were not surprising during this study, as performance in this task is dependent on hippocampal function. The hippocampus has consistently been described as being affected by hypoperfusion [36,58]. Furthermore, folic acid deficiency results in hippocampal neurodegeneration $[33,60]$. Therefore, the cumulative effect of FADD, chronic hypoperfusion, and impaired DNA repair on newly dividing neurons within the dentate gyrus [61] all likely contributed to the learning deficits we observed in the MWM. We also observed large increases in GFAP immunoreactivity in the dentate gyrus of Ung-/- mice with hypoperfusion on a FADD. However, upregulated GFAP activity was also observed, albeit to a lesser degree, in both 
hypoperfused mice on a $\mathrm{CD}$ and sham mice on a FADD, indicating that both diet and hypoperfusion are capable of inducing low levels of reactive gliosis. This is in agreement with previous studies that reported increased GFAP expression in the white matter of hypoperfused mice [35,58], and following dietary folic acid depletion [62].

Increased blood brain barrier (BBB) permeability has previously been reported in patients with vascular cognitive impairment [63]. In the present study we observed increased cortical protein levels of MMP-9 in Ung+/+ and Ung-/- mice on a FADD, as well as in hyoperfused Ung-/mice on a $\mathrm{CD}$, although not in other brain regions (e.g. hippocampus, striatum) that we measured. MMPs are known for their role in disrupting the extracellular matrix [64] and the BBB [63]. However, it is important to note that MMPs are also involved in promoting recovery [63]. A further study to determine the role MMP-9 plays in chronic hypoperfusion would be to induce this damage model in MMP-9 knockout mice. IQSEC1(mRNA) and subsequent Arf6 (protein) are highly expressed in the brain [65]. This molecule is involved in actin dynamics, lipid modification and membrane trafficking, specifically axonal transport after damage $[66,67]$. We found that IQSEC1 mRNA expression was increased in hypoperfused Ung-/- animals. Altered expression has been described previously in patients with AD, Parkinson's, and Huntington's disease [68], as well as animal models of neurodegeneration [69], however, investigation of this cell signaling molecule in the neurodegeneration field is relatively novel. As previously suggested, the changes in mRNA expression of IQSEC1 may not be biologically significant, since there was a small difference in fold change between sham and hypoperfused mice. This was further confirmed when we do not observe differences in protein levels ofArf6.

The fact that we observed a limited phenotype in response to chronic hypoperfusion alone was unexpected and requires further investigation. We propose that the combined effect of folate 
deficiency and elevated levels of plasma homocysteine likely exacerbate any underlying deficiencies that may be produced by hypoperfusion. Increases in homocysteine can be a result of deficiencies in vitamins (e.g. folates) and nutrients (e.g. choline), which not only remethylate homocysteine back to methionine, but have additional roles in the brain that could produce additional negative effects. For example folate also plays a significant role in DNA repair, specifically the conversion of dUMP to dTMP. Furthermore, elevated levels of plasma homocysteine may represent a marker for something else, such as changes in blood pressure [70]. In our case, to observe a behavioral phenotype, genetic Ung deficiency was also required. This is not surprising, as other studies have shown that genetic mouse models for AD are more susceptible to increased neuronal damage and impaired behavioral phenotype when they have elevated levels of plasma homocysteine [71,72]. This is the first study that reports sex differences using chronic hypoperfusion. According to the data, the behavior of females is more affected bythe UNG deficiency and chronic hypoperfusion. For future studies, it might be worthwhile to monitor the estrus cycle of the females during the course of the experiment.

In conclusion elevated levels of homocysteine via dietary folic acid deficiency and chronic hypoperfusion negatively affect learning in Ung deficient mice, while increasing GFAP immunoreactivity within the dentate gyrus of the hippocampus. Increased MMP-9protein levels in the cortex of folate deficient mice suggest initiation of BBB disruption, which is exacerbated by hypoperfusion in UNG deficient mice. This study is the first to show the negative effects of elevated levels of plasma homocysteine on chronic hypo-perfusion. Future studies may be warranted to further develop the hypoperfusion model.

\section{ACKNOWLEDGEMENTS}

The authors would like to thank Dr. Dirk Megow for technical assistance with plasma homocysteine measurements, Drs. Ben van Houten and Joel Meyer for advice on mitochondrial DNA damage experiments, Abinaya Ravishankar and Kevin Dam for assistance with data 
analysis and Susanne Mueller for MRI data collection. NMJ was funded by the Fonds de recherche du Québec Santé, Canada. TDF was supported by the German Federal Ministry of Education and Research (01EO0801, Center for Stroke Research Berlin) and 01EW1201 under the European Research Area Network Neuron scheme. AAK was funded by the Erasmus Mundus Master Program in Neuroscience.

\begin{abstract}
AUTHOR CONTRIBUTIONS
NMJ, TDF, MFü and UD designed the experiments. JL performed all PCR experiments for genotyping and behavioral data was collected by NMJ, MFü, and AAK. NMJ and AAK analyzed the behavioral data. MF performed surgery and MRI data was collected by TDF and PBS. Data analysis was performed by NMJ, TDF and AAK. NMJ, MFü and JL collected tissue and quantitative real time PCR, Western blots and immunhistochemistry were performed by NMJ. NMJ, TDF, MFü, AAK, CH and UD took a part in writing the manuscript. All of the authors discussed the results and contributed to the final version of the paper, and have approved it.
\end{abstract}


FIGURE CAPTIONS

Table 1 Number of $U n g^{+/+}$and $U n g^{-/-}$mice per diet and surgery group

\begin{tabular}{c|c|c|c|c|c} 
Ung $^{+/+}$ & Sham & Microcoil & Ung $^{-/-}$ & Sham & Microcoil \\
\hline CD & 7 & 7 & CD & 15 & 15 \\
FADD & 7 & 7 & FADD & 14 & 15
\end{tabular}

$\mathrm{CD}$, control diet; FADD, folic acid deficient diet

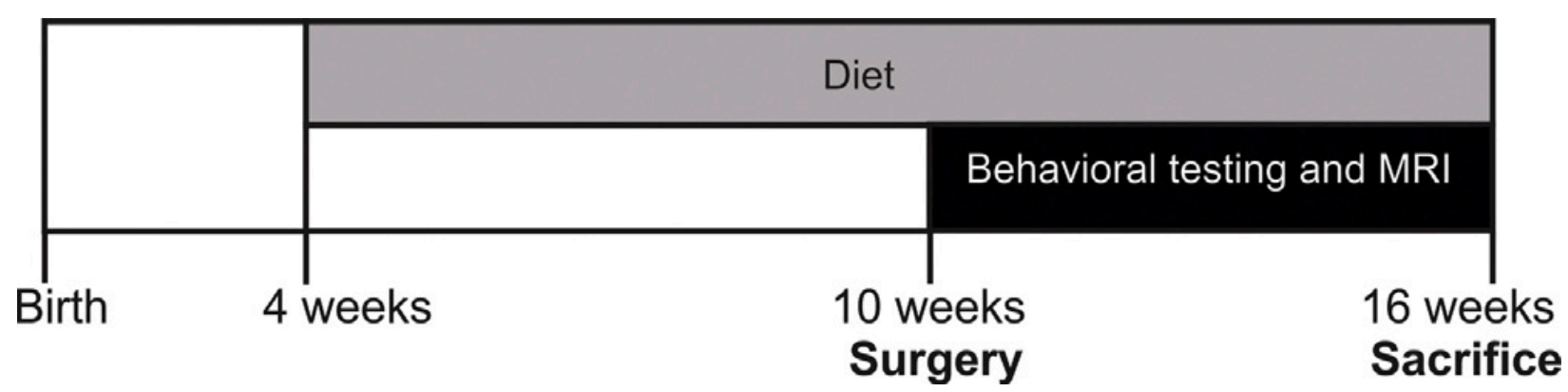

Figure 1. Experimental timeline illustrating the order of manipulations and outcome measures. Folic acid deficient (FADD) and control (CD) diets were provided starting 4-weeks after birth until completion of experiment. Mice were randomized to receive microcoil implantation on the carotid arteries to induce hypoperfusion (or the sham procedure) after 6 weeks of diet. Behavioral tests were completed over 3 weeks and included rotarod, the skilled ladder beam walking task, Morris water maze, elevated plus maze and open field. MRI imaging included volumetry and angiography measurements. Blood samples for plasma homocysteine measurements and brain tissue were collected at the conclusion of the experiments (16 weeks). 

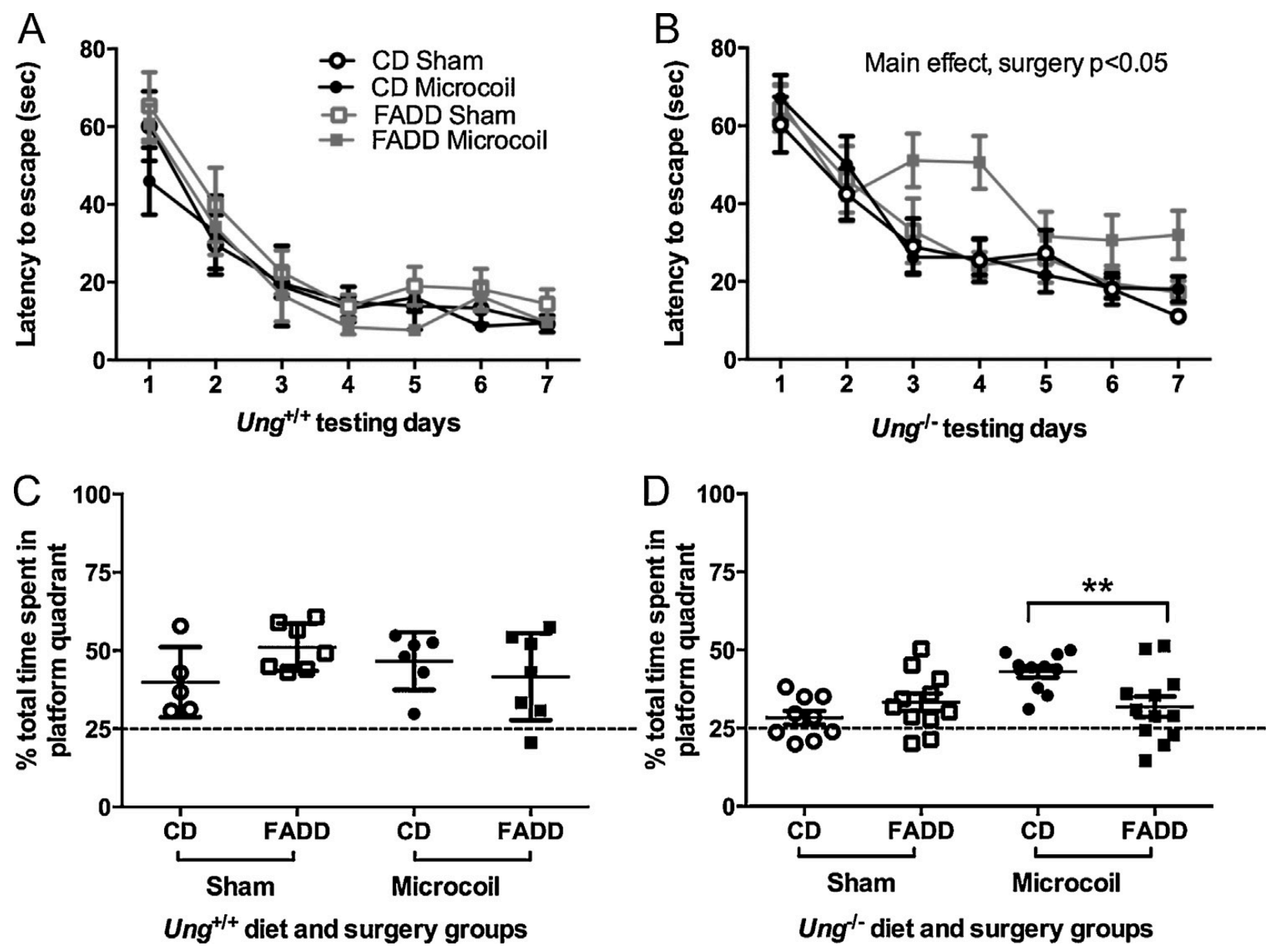

Figure 2. The effect of a folic acid deficient (FADD) or control diet (CD) and hypoperfusion on spatial learning and reference memory in Ung+/+ and Ung-/- mice. Morris water maze daily escape latencies in Ung $+/+$ (A) and Ung-/- (B) mice. Percent time spent in the target quadrant (scatter plot with mean \pm SEM of six to twelve mice per group) during the probe trial on day 8 in Ung $+/+(C)$ and Ung $-/-$ (D) mice. ${ }^{* *}$ Indicates $\mathrm{p}<0.01$, Bonferroni post-hoc test. 

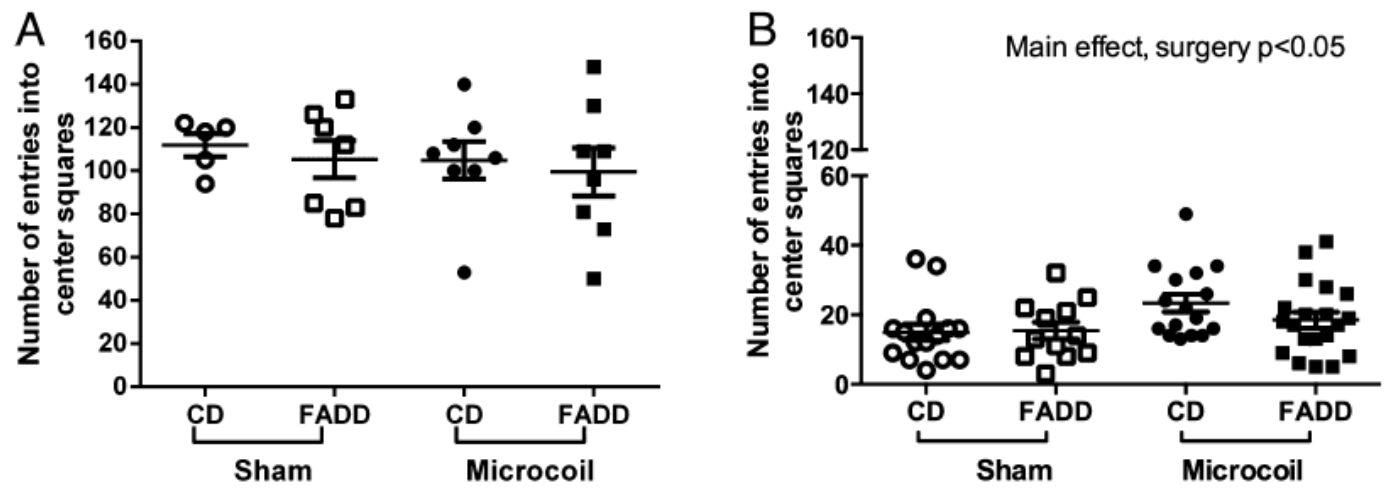

$\mathrm{Ung}^{+/+}$diet and surgery groups
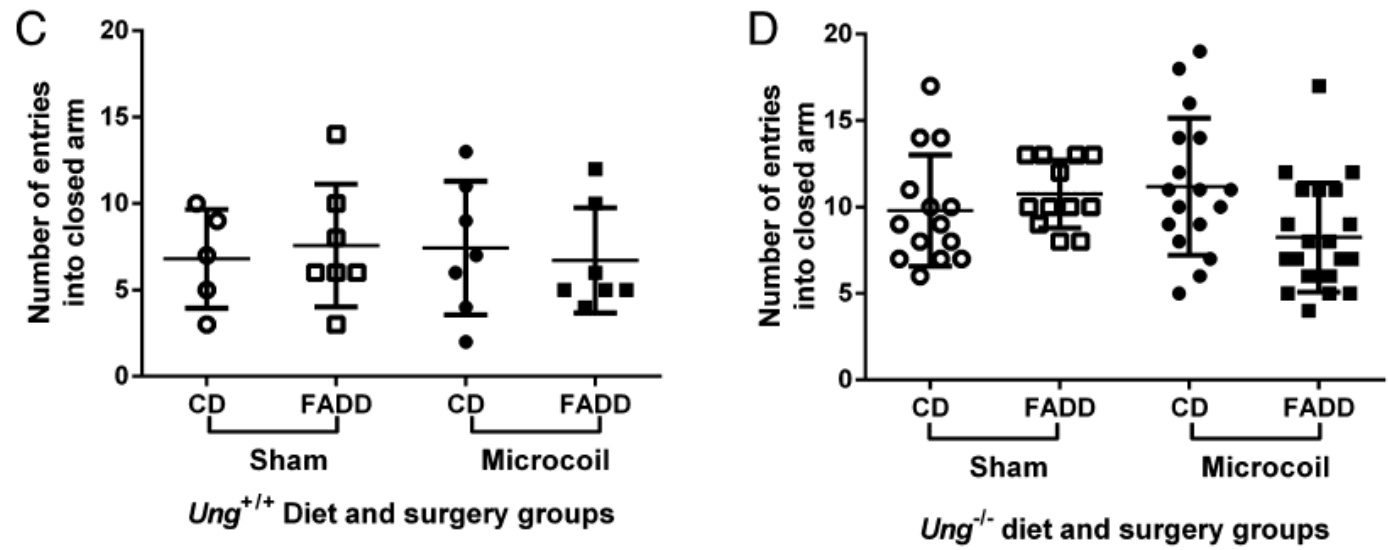

Figure 3. The effect of a folic acid deficient (FADD) or control diet (CD) and hypoperfusion on anxiety in Ung deficient mice. Number of entries into center squares of open field in Ung+/+ (A) and Ung-/- (B) mice. Number of entries into closed arm of elevated plus maze Ung+/+ (A) and Ung-/- (B) mice. Depicted are means \pm SEM of five to twenty-one mice per group. * Indicates $p$ $<0.05$, Bonferroni post-hoc test. 

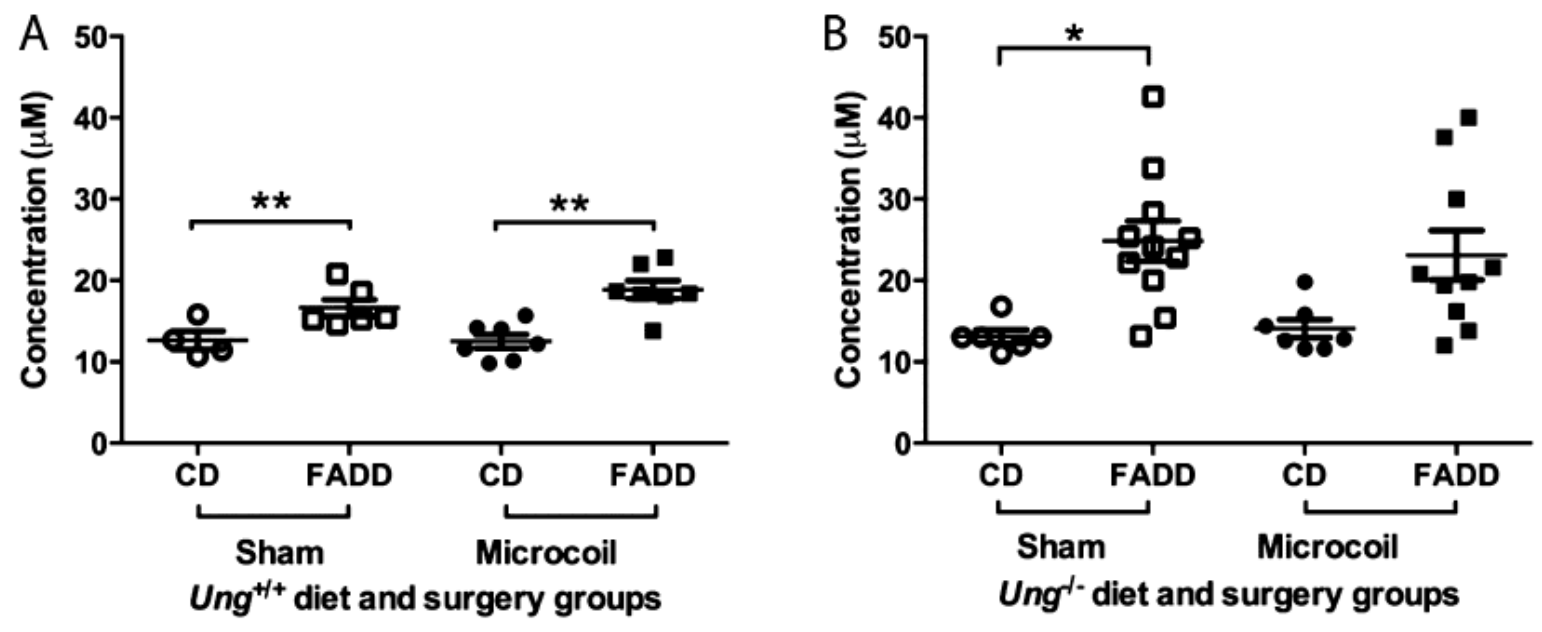

Figure 4. The effect of a folic acid deficient (FADD) or control diet (CD), and hypoperfusion on plasma homocysteine concentrations in Ung+/+ (A) and Ung-/- (B) mice. Depicted are means \pm SEM of six to eleven mice per group. ${ }^{*}$ Indicates $\mathrm{p}<0.05$ and ${ }^{* *}$ indicates $\mathrm{p}<0.01$, Bonferroni post-hoc test. Note: diet had the greatest influence on plasma homocysteine levels and Ung-/- mice on FADD had highest plasma homocysteine concentrations. 

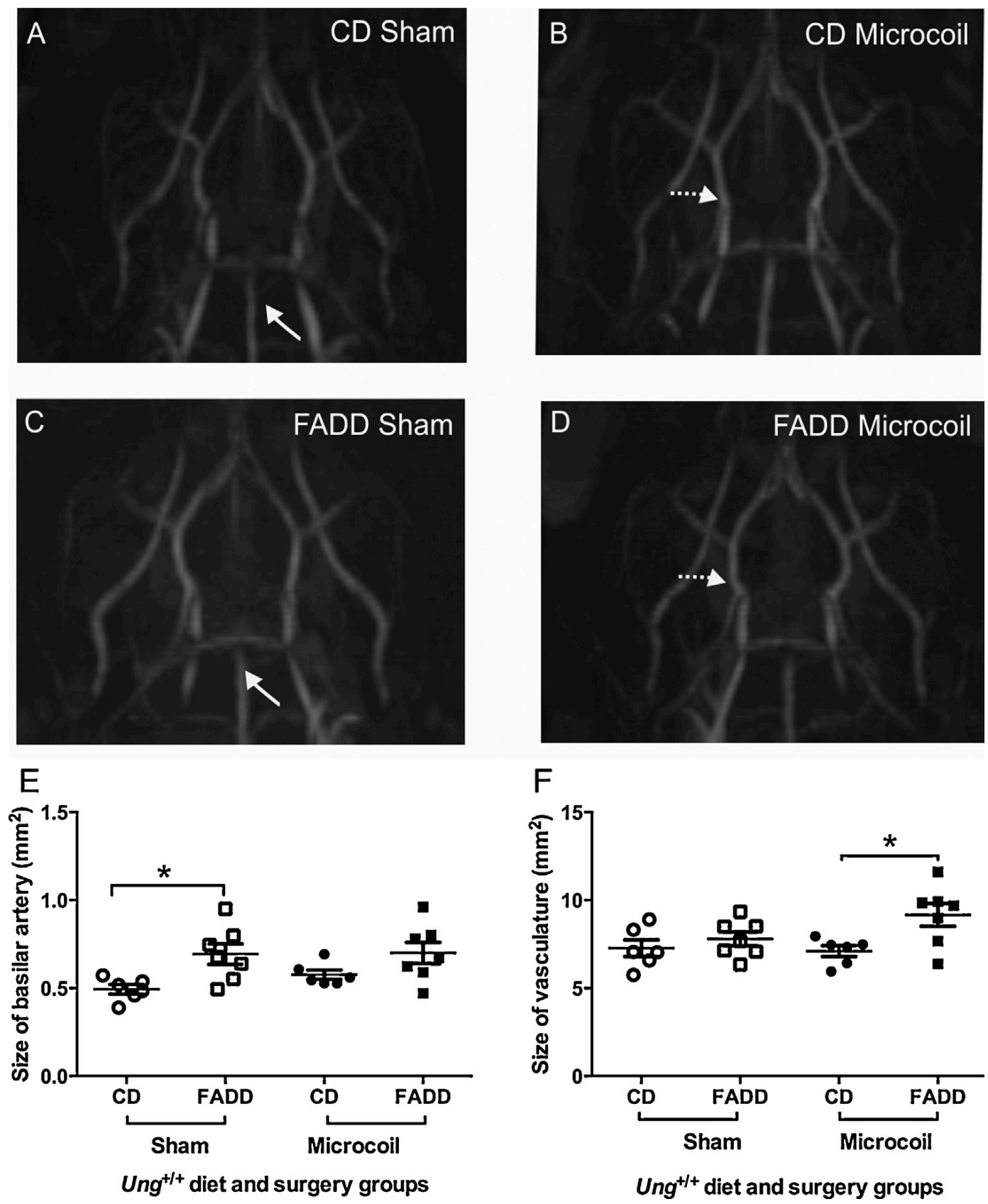

Figure 5. The effect of diet and hypoperfusion on arterial remodeling in Ung+/+ mice. Representative angiography images of the basilar artery and circle of Willis in Ung+/+ mice with a control diet (CD) (A) sham, (B) microcoil, and a folic acid deficient diet (FADD) (C) sham, (D) microcoil. Solid arrows indicate differences in basilar artery and dashed arrows indicate circle of Willis differences between groups. Size of the basilar artery (E) and the overall circle of Willis vasculature $(F)$. Depicted are means \pm SEM of six to seven mice per group. * Indicates $\mathrm{p}<$ 0.05, Bonferroni post-hoc test. 

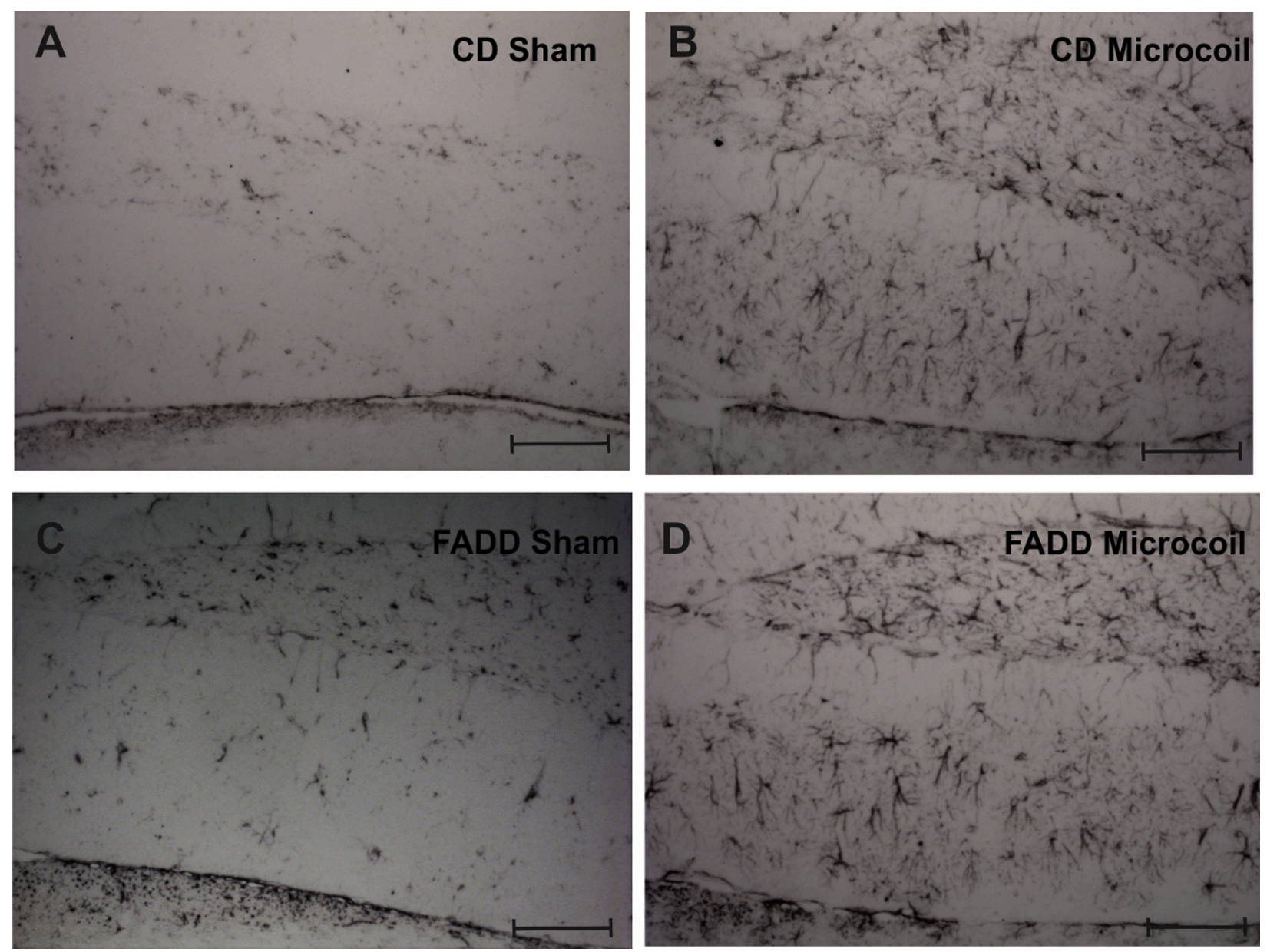

Figure 6. The effect of a folic acid deficient (FADD) or control diet (CD) and hypoperfusion on immunoreactivity of astrocytes in Ung-/- mice. Representative glial fibrillary acidic protein (GFAP) stained sections from the dentate gyrus within the hippocampus of a CD sham (A), CD microcoil (B), FADD sham (C) and FADD microcoil (D) mouse. All pictures at 200× magnification; scale bar $=10 \mu \mathrm{m}$. 

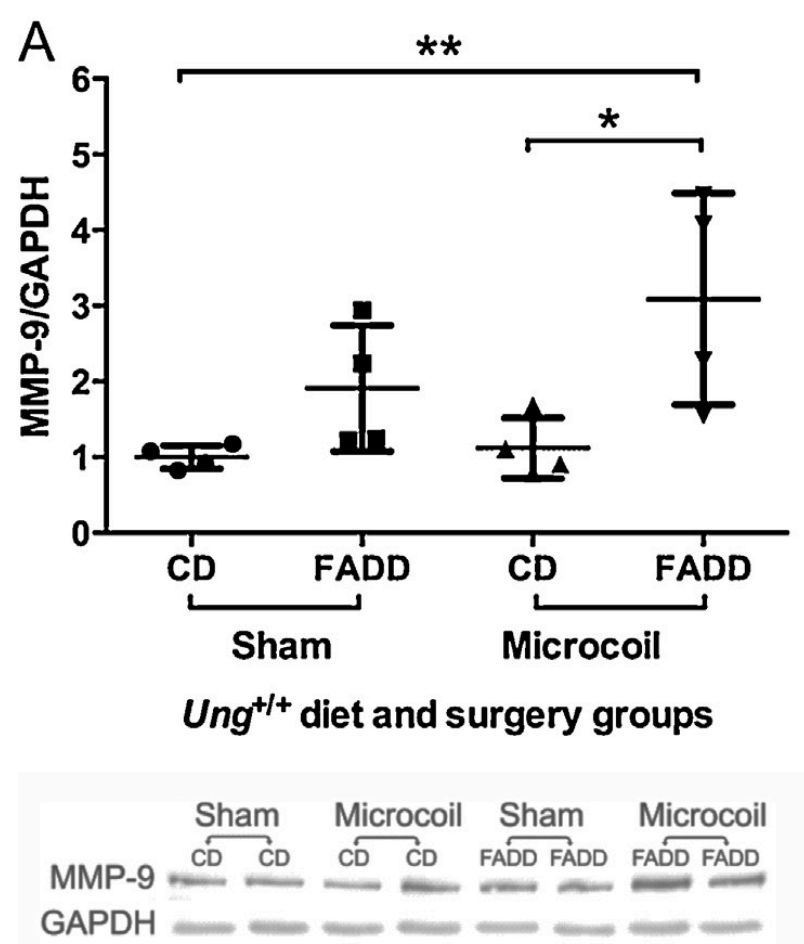
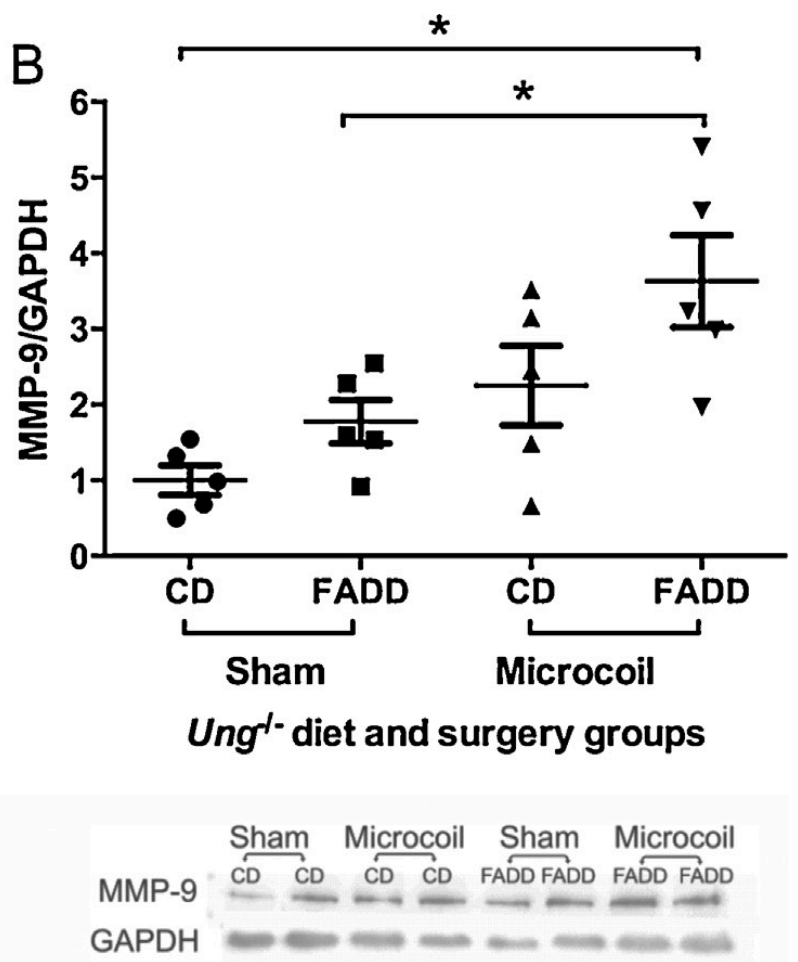

Figure 7. The effect of a folic acid deficient (FADD) or control diet (CD), and hypoperfusion on protein levels of metalloproteinase 9 (MMP-9) in cortical tissue in Ung+/+ (A) and Ung-/- (B) mice. Scatter plot with mean \pm S.E.M of 5 mice per group. * Indicates $\mathrm{p}<0.05$ and ${ }^{* *}$ indicates $\mathrm{p}<0.01$, Bonferroni post-hoc test. The panels below the graph depicted representative Western blot. 

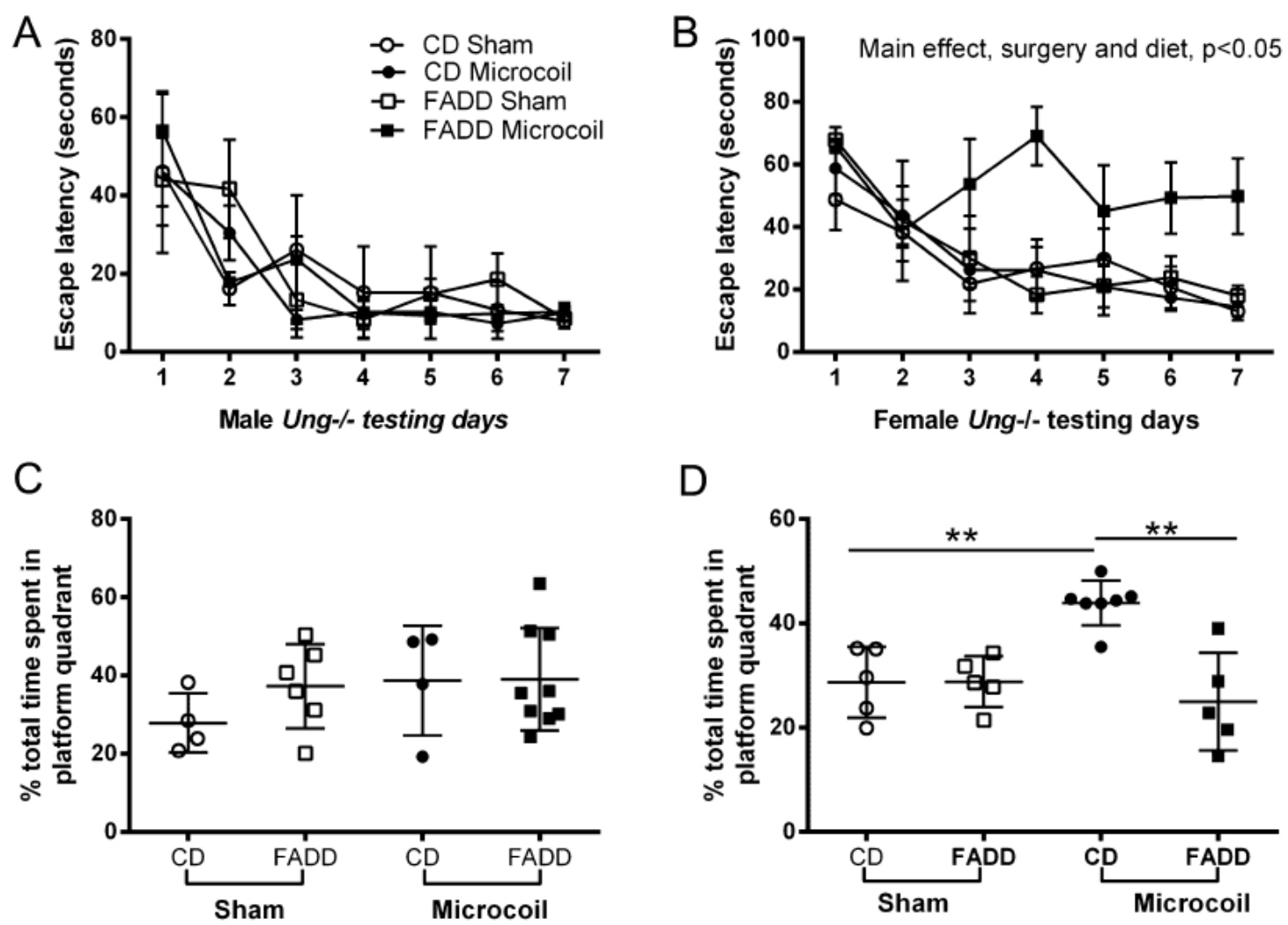

Male Ung-/- testing days
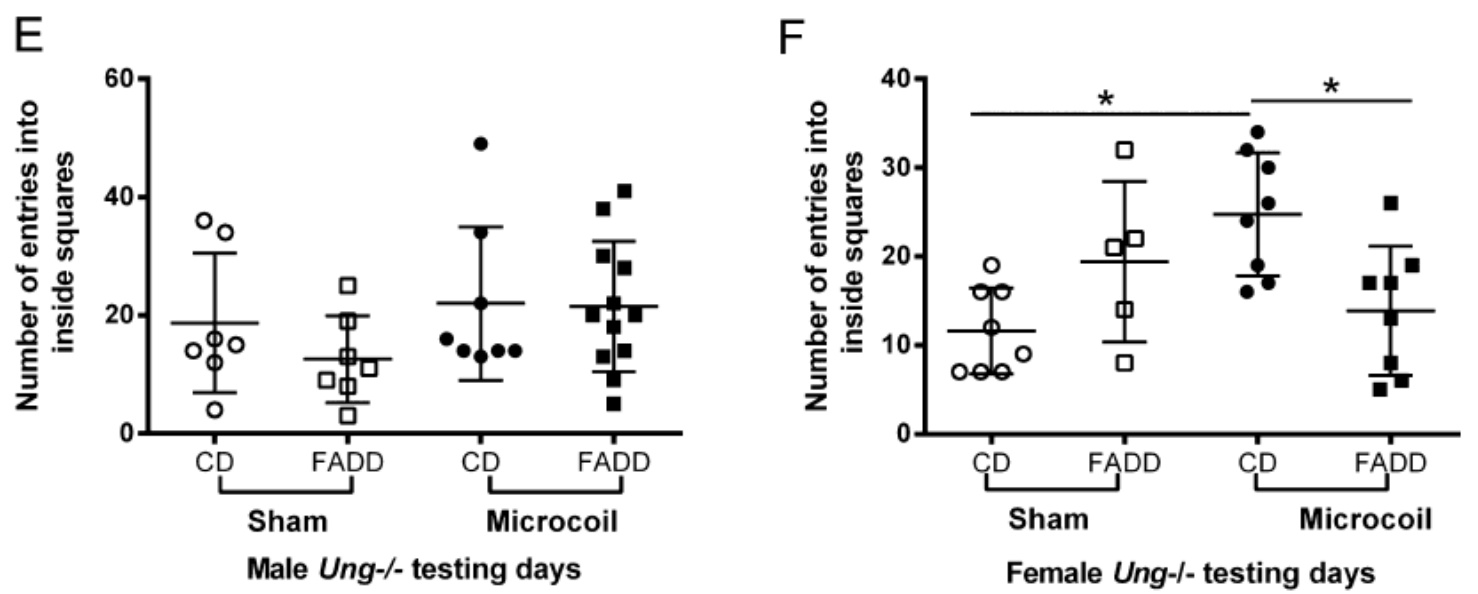

Figure 8. The effect of sex, folic acid deficient (FADD) or control diet (CD), and hypoperfusion on behavior of Ung-/- mice. Morris water maze (MWM) escape latency in males (A) and females (B). Percent total time spent in platform quadrant of MWM (C) males and females (D). Number of entries made into inside squares of open field (E) males and females (F). Scatter plot with mean \pm S.E.M of 5 to 8 mice per group. ${ }^{*}$ Indicates $\mathrm{p}<0.05$ and $* *$ indicates $\mathrm{p}<0.01$, Bonferroni post-hoc test. 


\section{REFERENCES}

[1] Bottiglieri T, Hyland K. S-adenosylmethionine levels in psychiatric and neurological disorders: a review. Acta Neurol Scand Suppl 1994;154:19-26.

[2] Castro R, Rivera I, Blom HJ, Jakobs C, Tavares de Almeida I. Homocysteinemetabolism, hyperhomocysteinaemia and vascular disease: an overview. JInherit Metab Dis 2006;29:320.

[3] Herrmann W, Obeid R. Homocysteine: a biomarker in neurodegenerative dis-eases. Clin Chem Lab Med 2011;49:435-41.

[4] Kong HY, Cheng DM, Pang W, Sun SD, Liu J, et al. Homocysteine lev-els and cognitive function scores measured with MMSE and BCAT of middle-aged and elderly subjects in Tianjin City. J Nutr Health Aging 2013;17:527-32.

[5] Elias MF, Sullivan LM, Agostino RBD, Elias PK, Jacques PF, et al. Homocysteine and cognitive performance in the Framingham offspring study: age is important. Am J Epidemiol 2005;162:644-53.

[6] Arlt S, Schwedhelm E, Kölsch H, Jahn H, Linnebank M, et al. Dimethylarginines, homocysteine metabolism, and cerebrospinal fluid markers for Alzheimer's disease. J Alzheimers Dis 2012;31:751-8.

[7] Hooshmand B, Solomon a, Kåreholt I, Leiviskä J, Rusanen M, et al. Homocysteine and holotranscobalamin and the risk of Alzheimer disease: a longitudinal study. Neurology 2010;75:1408-14.

[8] Irizarry MC, Gurol ME, Raju S, Diaz-Arrastia R, Locascio JJ, et al. Association of homocysteine with plasma amyloid beta protein in aging and neurodegenerative disease. Neurology 2005;65:1402-8.

[9] Nilsson K, Gustafson L, Hultberg B. Elevated plasma homocysteine level in vascular dementia reflects the vascular disease process. Dement Geriatr Cogn Dis Extra 2013;3:1624.

[10] Perez L, Heim L, Sherzai A, Jaceldo-Siegl K. Nutrition and vascular dementia. J Nutr Health Aging 2012;16:319-24.

[11] Smith AD. The worldwide challenge of the dementias: a role for B vitamins and homocysteine? Food Nutr Bull 2008;29:S143-72.

[12] West RK, Beeri MS, Schmeidler J, Mitchell DB, Carlisle KR, et al. Homocysteine and cognitive function in very elderly non demented subjects. Am J Geriatr Psychiatry 2011;19:673-7.

[13] Ho RCM, Cheung MWL, Fu E, Win HH, Zaw MH, et al. Is high homocysteine level a risk factor for cognitive decline in elderly? A systematic review, meta-analysis, and metaregression. Am J Geriatr Psychiatry 2011;19:607-17. 
[14] Mooijaart SP, Gussekloo J, Frölich M, Jolles J, Stott DJ, et al. Homocysteine, vita-min B12, and folic acid and the risk of cognitive decline in old age: the Leiden85-Plus study. Am J Clin Nutr 2005;82:866-71.

[15] Jadavji NM, Bahous RH, Deng L, Malysheva O, Grand'maison M, et al. Mouse model for deficiency of methionine synthase reductase exhibits short-term memory impairment and disturbances in brain choline metabolism. BiochemJ 2014;461:205-12.

[16] Jadavji NM, Deng L, Leclerc D, Malysheva O, Bedell BJ, et al. Severe methylenetetrahydrofolate reductase deficiency in mice results in behavioral anomalies with morphological and biochemical changes in hippocampus. Mol Genet Metab 2012;106:14959.

[17] Sudduth TL, Powell DK, Smith CD, Greenstein A, Wilcock DM. Induction of hyperhomocysteinemia models vascular dementia by induction of cerebral microhemorrhages and neuroinflammation. J Cereb Blood Flow Metab 2013;33:708-15.

[18] Troen AM, Shea-Budgell M, Shukitt-Hale B, Smith DE, Selhub J, et al. B-vitamin deficiency causes hyperhomocysteinemia and vascular cognitive impairment in mice. Proc Natl Acad Sci USA 2008;105:12474-9.

[19] Ho P. Folate deprivation induces neurodegeneration: roles of oxidative stress and increased homocysteine. Neurobiol Dis 2003;14:32-42.

[20] Chan A, Tchantchou F, Graves V, Rozen R, Shea TB. Dietary and genetic com-promise in folate availability reduces acetylcholine, cognitive performance and increases aggression: critical role of S-adenosyl methionine. J Nutr Health Aging 2008;12:252-61.

[21] Schlaich MP, John S, Jacobi J, Lackner KJ, Schmieder RE. Mildly elevated homocysteine concentrations impair endothelium dependent vasodilation in hypercholesterolemic patients. Atherosclerosis 2000;153:383-9.

[22] Kubová H, Folbergrová J, Mares P. Seizures induced by homocysteine in rats during ontogenesis. Epilepsia 1995;36:750-6.

[23] Bełtowski J. Protein homocysteinylation: a new mechanism of atherogenesis? Postepy Hig Med Dosw (Online) 2005;59:392-404.

[24] Petras M, Tatarkova Z, Kovalska M, Mokra D, Dobrota D, et al. Hyperhomocysteinemia as a risk factor for the neuronal system disorders. J Physiol Pharmacol 2014;65:15-23.

[25] Chen Z, Schwahn BC, Wu Q, He X, Rozen R. Postnatal cerebellar defects in mice deficient in methylenetetrahydrofolate reductase. Int J Dev Neurosci 2005;23:465-74.

[26] Axelrod J. Methylation reactions in the formation and metabolism of catecholamines and other biogenic amines. Pharmacol Rev 1966;18:95-113.

[27] Knock E, Deng L, Wu Q, Lawrance AK, Wang X, et al. Strain differences in mice highlight the role of DNA damage in neoplasia induced by low dietary folate. JNutr 2008;138:653-8. 
[28] Fenech M. Folate, DNA damage and the aging brain. Mech Ageing Dev 2010;131:236-41.

[29] Houtgraaf JH, Versmissen J, van der Giessen WJ. A concise review of DNA damage checkpoints and repair in mammalian cells. Cardiovasc Revasc Med 2006;7:165-72 (3).

[30] Fishel ML, Vasko MR, Kelley MR. DNA repair in neurons: so if they don't divide what's to repair? Mutat Res 2007;614:24-36.

[31] Kavli B, Sundheim O, Akbari M, Otterlei M, Nilsen H, et al. hUNG2 is the major repair enzyme for removal of uracil from U:A matches, U:G mismatches, and $U$ in single-stranded DNA, with hSMUG1 as a broad specificity backup. J Biol Chem 2002;277:39926-36.

[32] Kruman II, Schwartz E, Kruman Y, Cutler RG, Zhu X, et al. Suppression of uracil-DNA glycosylase induces neuronal apoptosis. J Biol Chem 2004;279:43952-60.

[33] Kronenberg G, Harms C, Sobol RW, Cardozo-Pelaez F, Linhart H, et al. Folate deficiency induces neurodegeneration and brain dysfunction in mice lacking uracil DNA glycosylase. J Neurosci 2008;28:7219-30.

[34] Endres M, Ahmadi M, Kruman I, Biniszkiewicz D, Meisel A, et al. Folate deficiency increases post ischemic brain injury. Stroke 2005;36:321-5.

[35] Shibata M, Ohtani R, Ihara M, Tomimoto H. White matter lesions and glial activation in a novel mouse model of chronic cerebral hypoperfusion. Stroke 2004;35:2598-603.

[36] Nishio K, Ihara M, Yamasaki N, Kalaria RN, Maki T, et al. A mouse model characterizing features of vascular dementia with hippocampal atrophy. Stroke 2010;41:1278-84.

[37] Coltman R, Spain A, Tsenkina Y, Fowler JH, Smith J, et al. Selective white matter pathology induces a specific impairment in spatial working memory. Neurobiol Aging 2011;32:2324.e7-12.

[38] Endres M, Biniszkiewicz D, Sobol RW, Harms C, Ahmadi M, et al. Increased postischemic brain injury in mice deficient in uracil-DNA glycosylase. J Clin Invest 2004;113:1711-21.

[39] Li D, Rozen R. Biochemical, molecular, and genetic mechanisms maternal folate deficiency affects proliferation, but not apoptosis, in embryonic mouse heart1. J Nutr 2006;136:17748.

[40] Devlin AM, Arning E, Bottiglieri T, Faraci FM, Rozen R, et al. Effect of MTHFR genotype on diet-induced hyperhomocysteinemia and vascular function in mice. Blood 2004;103:2624-9.

[41] Balkaya M, Kröber J, Gertz K, Peruzzaro S, Endres M. Characterization of long-term functional outcome in a murine model of mild brain ischemia. J Neurosci Methods 2013;213:179-87.

[42] Farr TD, Liu L, Colwell KL, Whishaw IQ, Metz GA. Bilateral alteration in stepping pattern after unilateral motor cortex injury: a new test strategy for analysis of skilled limb movements in neurological mouse models. J Neurosci Methods2006;153:104-13. 
[43] Morris R. Developments of a water-maze procedure for studying spatial learning in the rat. J Neurosci Methods 1984;11:47-60.

[44] Bignami G. Economical test methods for developmental neurobehavioral toxicity. Environ Health Perspect 1996;104(Suppl.):285-98.

[45] Walf AA, Frye CA. The use of the elevated plus maze as an assay of anxiety-related behavior in rodents. Nat Protoc 2007;2:322-8.

[46] Knock E, Deng L, Wu Q, Leclerc D, Wang X, et al. Low dietary folate initiates intestinal tumors in mice, with altered expression of G2-M check-point regulators polo-like kinase 1 and cell division cycle 25c. Cancer Res2006;66:10349-56.

[47] Santos JH, Meyer JN, Mandavilli BS, Van Houten B. Quantitative PCR-based measurement of nuclear and mitochondrial DNA damage and repair in mammalian cells. Methods Mol Biol 2006:183-99 (DNA repair protocols: mammalian systems).

[48] Schoemaker RG, Smits JF. Behavioral changes following chronic myocardial infarction in rats. Physiol Behav 1994;56:585-9.

[49] Tusher VG, Tibshirani R, Chu G. Significance analysis of microarrays applied to the ionizing radiation response. Proc Natl Acad Sci USA 2001;98:5116-21.

[50] Kronenberg G, Gertz K, Overall RW, Harms C, Klein J, et al. Folate deficiency increases mtDNA and D-1 mtDNA deletion in aged brain of mice lacking uracil-DNA glycosylase. Exp Neurol 2011;228:253-8.

[51] Lauritzen KH, Moldestad O, Eide L, Carlsen H, Nesse G, et al. Mitochondrial DNA toxicity in forebrain neurons causes apoptosis, neurodegeneration, and impaired behavior. Mol Cell Biol 2010;30:1357-67.

[52] Whalley LJ, Duthie SJ, Collins AR, Starr JM, Deary IJ, et al. Homocysteine, antioxidant micronutrients and late onset dementia. Eur J Nutr 2013;53:277-85.

[53] Busch H-J, Buschmann IR, Mies G, Bode C, Hossmann K-A. Arteriogenesis in the hypoperfused rat brain. J Cereb Blood Flow Metab 2003;23:621-8.

[54] Soria G, Tudela R, Márquez-Martín A, Camón L, Batalle D, et al. The ins and outs of the BCCAo model for chronic hypoperfusion: a multimodal and longitudinal MRI approach. PLoS ONE 2013;8:e74631.

[55] Tyagi SC, Lominadze D, Roberts AM. Homocysteine in microvascular endothelial cell barrier permeability. Cell Biochem Biophys 2005;43:37-44.

[56] Reynolds E. Vitamin B12, folic acid, and the nervous system. Lancet Neurol2006;5:949-60.

[57] Yamada M, Ihara M, Okamoto Y, Maki T, Washida K, et al. The influence of chronic cerebral hypoperfusion on cognitive function and amyloid $\beta$ metabolism in APP overexpressing mice. PLoS ONE 2011;6:e16567. 
[58] Miki K, Ishibashi S, Sun L, Xu H, Ohashi W, et al. Intensity of chronic cerebral hypoperfusion determines white/gray matter injury and cognitive/motor dysfunction in mice. J Neurosci Res 2009;87:1270-81.

[59] Shepherd JK, Grewal SS, Fletcher A, Bill DJ, Dourish CT. Behavioural and pharmacological characterisation of the elevated "zero-maze" as an animal model of anxiety. Psychopharmacology (Berl) 1994;116:56-64.

[60] Kruman II, Mouton PR, Emokpae R, Cutler RG, Mattson MP. Folate deficiency inhibits proliferation of adult hippocampal progenitors. NeuroRepor2005;16:1055-9.

[61] Kempermann G. New neurons for "survival of the fittest". Nat Rev Neurosci 2012;13:72736.

[62] Hwang IK, Yoo K-Y, Suh H-W, Kim YS, Kwon DY, et al. Folic acid deficiency increases delayed neuronal death, DNA damage, platelet endothelial cell adhesion molecule-1 immunoreactivity, and gliosis in the hippocampus after transient cerebral ischemia. J Neurosci Res 2008;86:2003-15.

[63] Rosenberg Ga. Matrix metalloproteinases and their multiple roles in neurodegenerative diseases. Lancet Neurol 2009;8:205-16.

[64] Bonneh-Barkay D, Wiley CA. Brain extracellular matrix in neurodegeneration. Brain Pathol 2009; 19:573-85.

[65] Choi S, Ko J, Lee J-R, Lee HW, Kim K, et al. ARF6 and EFA6A regulate the development and maintenance of dendritic spines. J Neurosci 2006;26:4811-9.

[66] Jaworski J. ARF6 in the nervous system. Eur J Cell Biol 2007;86:513-24.

[67] Eva R, Crisp S, Marland JRK, Norman JC, Kanamarlapudi V, et al. ARF6 directs axon transport and traffic of integrins and regulates axon growth in adult DRG neurons. $\mathrm{J}$ Neurosci 2012;32:10352-64.

[68] Russ J. Systematic interaction mapping reveals novel modifiers of neurodegenerative disease processes. Berlin: Humboldt-Universität zu Berlin; 2012.

[69] Sannerud R, Declerck I, Peric A, Raemaekers T, Menendez G, et al. ADP ribosylation factor 6 (ARF6) controls amyloid precursor protein (APP) processing by mediating the endosomal sorting of BACE1. Proc Natl Acad Sci USA2011;108:E559-68.

[70] Ward M, Wilson CP, Strain JJ, Horigan G, Scott JM, et al. tetrahydrofolate reductase (MTHFR) and hypertension. Int J Vitam Nutr Res 2011;81:240-4.

[71] Li J-G, Praticò D. High levels of homocysteine results in cerebral amyloid angiopathy in mice. J Alzheimers Dis 2015;43. PMID: 25061050.

[72] Farkas M, Keskitalo S, Smith DEC, Bain N, Semmler A, et al. Hyperhomocysteinemia in Alzheimer's disease: the hen and the egg? J Alzheimers Dis2013;33:1097-104. 
